\title{
ОПРЕДЕЛЕНИЕ ОПТИМАЛЬНОЙ СТРУКТУРЫ ВЕТРОСОЛНЕЧНЫХ ЭЛЕКТРОСТАНЦИЙ В МОНГОЛЬСКОЙ ЧАСТИ ПУСТЫНИ ГОБИ
}

\author{
Марченко Олег Владимирович1, \\ marchenko@isem.irk.ru \\ Соломин Сергей Владимирович1, \\ solomin@isem.irk.ru \\ 1 Институт систем энергетики им. Л.А. Мелентьева Сибирского отделения Российской академии наук, \\ Россия, 664033, г. Иркутск, ул. Лермонтова, 130.
}

\begin{abstract}
Актуальность работы обусловлена интенсивным экономическим развитием стран Северо-Восточной Азии, увеличением их потребности в электроэнергии и иелесообразностью повышения экономической и экологической эффрективности электроснабжения за счет реализации проектов электроэнергетической интеграции. При этом важную роль может играть широкомаситабное внедрение возобновляемых источников энергии.

Цель: определение оптимальной структуры ветросолнечных электростанций в монгольской части пустьни Гоби (соотношения мощностей электростанций разных типов и выработки ими электроэнергии) для разных сочетаний экономических и климатических условий.

Методы: систематизация климатической и метеорологической информации, предварительная оценка эффективности энергоисточников разных типов по критерию стоимости производимой электроэнергии, математическое моделирование структуры и режимов работы энергосистемы. Математическая модель учитывает случайный характер поступления солнечной и ветровой энергии.

Результаты. Показано, что произведенная фотоэлектрическими преобразователями и ветротурбинами электроэнергия с учетом стоимости ее транспорта по линиям электропередачи конкурентоспособна на электроэнергетических рынках Китая и других стран Северо-Восточной Азии. Для различных значений прихода солнечной радиации и скорости ветра определены оптимальные соотношения между мощностями возобновляемых источников энергии, производством электроэнергии фотоэлектрическими преобразователями и ветротурбинами, а также поставками электроэнергии из энергосистемы Китая для компенсации неравномерности выработки возобновляемых источников энергии. Показана экономическая эффрективность совместного использования солнечной и ветровой энергии в монгольской части пустыни Гоби за исключением некоторых районов с низкими скоростями ветра. Совместное использование солнечной и ветровой энергии позволяет снизить суммарные затраты на систему электроснабжения более чем на четверть по сравнению с вариантом использования только солнечной энергии.
\end{abstract}

Ключевые слова:

Пустыня Гоби, Монголия, энергосистема, возобновляемые источники энергии, эфффективность, цена электроэнергии.

\section{Введение}

В настоящее время активно обсуждаются вопросы электроэнергетической интеграции производителей и потребителей электрической энергии в СевероВосточной Азии [1-3], которая может обеспечить как экономический, так и экологический эффект. В рамках проектов интеграции предполагается использование возобновляемых источников энергии (ВИЭ), что позволит значительно снизить выбросы в окружающую среду вредных веществ, в том числе диоксида углерода, ответственного за изменение климата [3-6].

Один из таких проектов предполагает крупномасштабное строительство солнечных и ветровых электростанций (суммарной мощностью до 100 ГВТ) в монгольской части пустыни Гоби и последующий экспорт электроэнергии в сопредельные страны [1, 5-7]. Ввод в эксплуатацию большого количества ВИЭ, в частности фотоэлектрических преобразователей (ФЭП), может привести к локальным изменениям температурного режима [8] и дополнительно осложняется в условиях пустыни ускоренной эрозией почвы и пыльными бурями, существенно влияющими на производство и потребление энергии [9]. Климат пустыни Гоби рез- ко- континентальный, с большим сезонным перепадом температур, что неблагоприятно для солнечных и ветровых электростанций. Однако эти технические трудности преодолимы [4], и наиболее серьезным вопросом остается экономическая эффективность и конкурентоспособность проекта. Ранее выполненные предварительные оценки [10] показали, что солнечные электростанции пока еще уступают по экономичности электростанциям на органическом топливе. Однако за прошедшие годы успехи в развитии технологии производства солнечных элементов привели к существенному удешевлению ФЭП.

$\mathrm{B}$ связи с этим в настоящей работе на основе современных технико-экономических показателей энергоисточников проведены исследования структуры ветросолнечных электростанций для условий монгольской части пустыни Гоби и эффективности их применения в зависимости от внешних условий.

Пустыня Гоби расположена на расстоянии 400-430 км от столицы Монголии Улан-Батора и 650-750 км от столицы Китая Пекина (рис. 1). При полном использовании энергетического потенциала этого района мощность солнечных электростанций на 
основе ФЭП может достигнуть 1500 ГВт, а ветроэнергетических установок (ВЭУ) - 1100 ГВт $[6,7]$. Средняя плотность энергии при этом составит 66 $\mathrm{MBT} / \mathrm{\kappa м}^{2}$ для солнечной энергии и $7 \mathrm{MBT} /$ км $^{2}$ для ветровой энергии [7]. В 2017-2018 гг. в пустыне Гоби введены в строй 2 ветропарка суммарной мощностью 105 МВт (Цэций и Сайншанд) и 4 солнечные электростанции мощностью 75 МВт.

Максимум электрической нагрузки в Монголии не превышает 1 ГВт, в соседних странах он существенно выше. Установленная мощность электростанций в 2016 г.: в Китае - 1146 ГВт, в Японии - 302 ГВт, в России - 232 ГВт, в Южной Корее - 94 ГВт, в Северной Корее - 9 ГВт [11].

Потребление электроэнергии в Монголии также существенно меньше, чем в других странах СевероВосточной Азии. Электропотребление в Китае превышает уровень Монголии в 910 раз, в Японии оно выше в 166 раз, в Южной Корее - в 88 раз, в России в 155 раз, в соседних российских регионах (Сибирь и
Дальний Восток) - в 43 раза [12]. В Монголии самый низкий среди стран Северо-Восточной Азии средний тариф на электроэнергию (около 5 цент/кВт.ч) по сравнению с 7,5 цент/кВт.ч в Китае, 8,5 цент/кВт.ч в Южной Корее и 16 цент/кВт.ч в Японии [11].

Общая мощность предложенных инвесторами проектов строительства ВЭУ и ФЭП в Монголии превышает 950 МВт и приближается к суммарной установленной мощности всех энергоисточников страны. В 2017 г. правительство Монголии объявило о введении льготного тарифа для стимулирования инвесторов ветровых и солнечных электростанций $(8-9,5$ и 15-18 цент/кВт.ч соответственно) с целью введения дополнительных мощностей ВЭУ (450 МВт) и ФЭП (200 МВт). Однако ряд экспертов выразили сомнения в способности потребителей оплачивать повышенные тарифы и возможности электроэнергетической системы Монголии поглотить такие значения переменной мощности возобновляемых источников энергии.

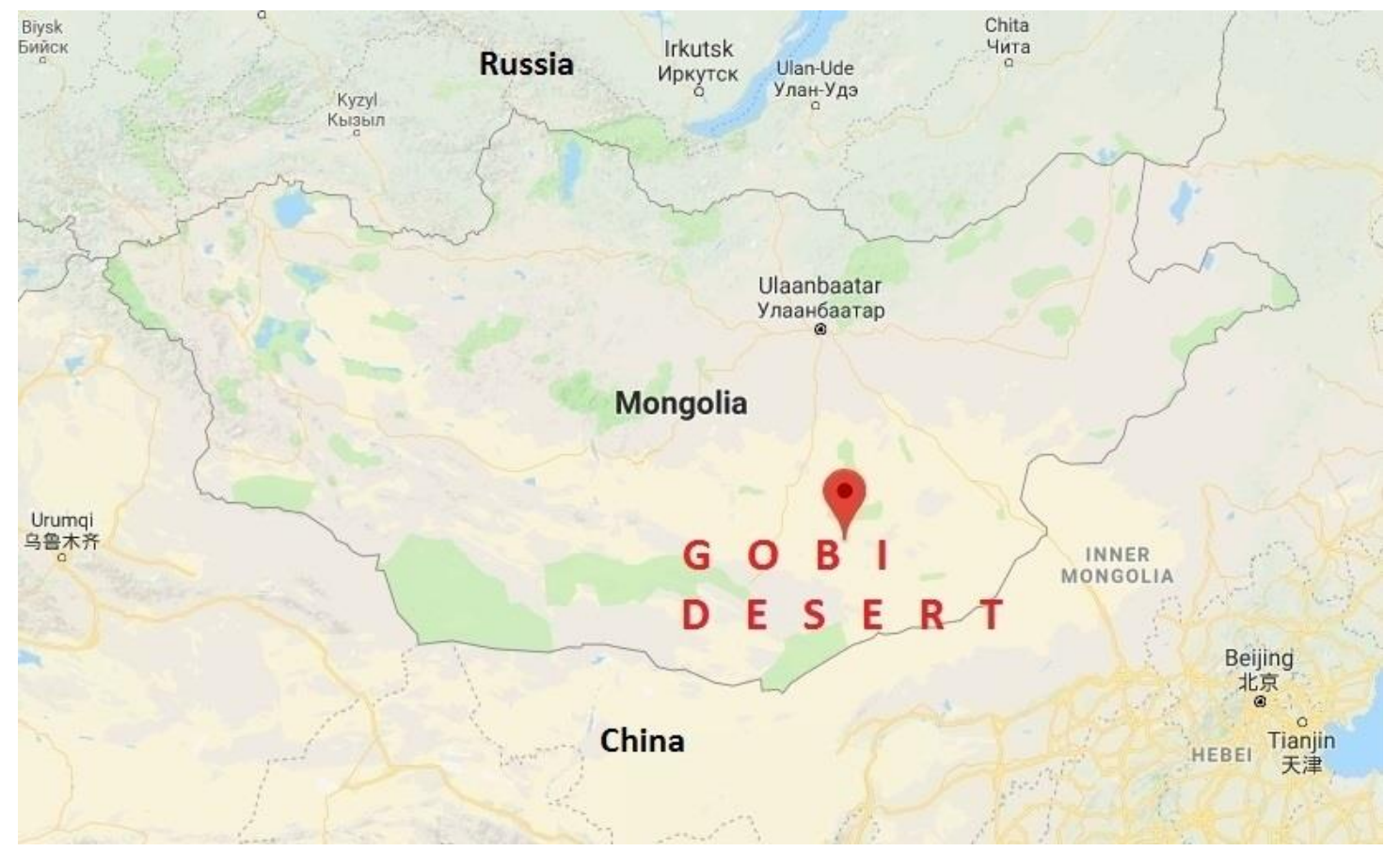

Puc. 1. Пустыня Гоби на карте Google Maps

Fig. 1. Gobi Desert on Google Maps

\section{Постановка задачи}

Цель работы - определение оптимальной структуры ветросолнечных электростанций (соотношения мощностей электростанций разных типов и выработки ими электроэнергии), расположенных в монгольской части пустыни Гоби и предназначенных для экспорта электроэнергии в сопредельные страны при разных сочетаниях экономических и климатических условий.

Решение задачи целесообразно разделить на два этапа. На первом этапе определялись удельные затраты на производство электроэнергии (стоимость электроэнергии) для энергоисточников разных типов. Это позволяет предварительно оценить и сравнить их экономическую эффективность. Затраты на единицу произведенной электроэнергии учитывают инвестиции, эксплуатационные издержки и плату за выбросы диоксида углерода $[13,14]$.

На втором этапе посредством математического моделирования учитывались системные эффекты, обусловленные совместной работой возобновляемых источников энергии. Оптимальная структура системы электроснабжения выбиралась из решения задачи математического программирования: минимизация затрат с учетом балансов энергии и ряда дополнительных ограничений. Разработанная для этой цели математическая модель отличается от моделей HOMER [15, 16], TRNSYS [17], HOGA [18] и др. [19-23] тем, 
что не требует предварительного задания стратегии выбора режимов работы отдельных элементов энергосистемы. Модель учитывает случайный характер поступления солнечной и ветровой энергии. Эти характеристики изменяются как по часам суток, так и по сезонам года. Непостоянство во времени выработки энергии ВИЭ делает целесообразным их совместное использование. Работа энергосистемы моделируется в динамике, с шагом по времени 1 час. Искомыми переменными являются установленные и текущие (в данный момент времени) мощности энергоисточников. Подробно модель описана в работах $[24,25]$.

Система электроснабжения (рис. 2) состоит из ФЭП, ВЭУ, преобразователей напряжения и средств сопряжения с сетью. Поскольку ветросолнечные электростанции в пустыне Гоби расположены вдали от центров нагрузки, произведенная электроэнергия передается в направлении Китая, условно в район Пекина. Для передачи энергии на большие расстояния наиболее эффективны ЛЭП постоянного тока $[5,6]$.

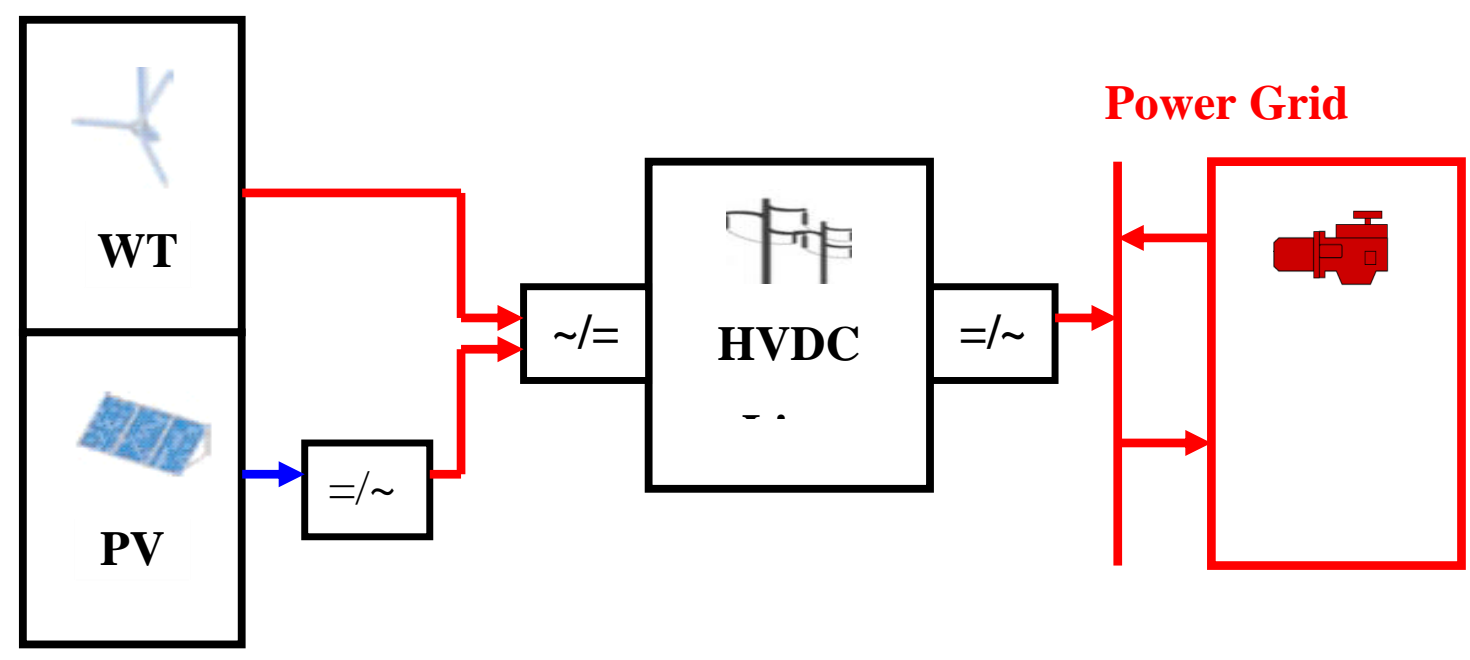

Puc. 2. Схема энергосистемы. WT-ВЭУ, РV-ФЭП, HVDC line - линия постоянного тока, Power Grid - электроэнергетическая система (сеть)

Fig. 2. Diagram of the power system. WT - wind turbines, PV - photovoltaic, HVDC - high-voltage direct current transmission line

Предполагается, что комплекс ветросолнечных электростанций будет представлять собой один из первых этапов электроэнергетической интеграции стран Северо-Восточной Азии. Он работает на потребителей, которые наряду с электроэнергией, производимой ВИЭ, потребляют также электроэнергию из систем Северного и Северо-Восточного Китая, которые компенсируют неравномерность выработки ВИЭ. Мощность этих электроэнергетических систем значительно больше мощности рассматриваемых ветросолнечных электростанций.

Мощность ВЭУ изменяется в зависимости от скорости ветра в соответствии с рабочей характеристикой, мощность ФЭП прямо пропорциональная интенсивности солнечного излучения с поправкой на температуру панелей.

\section{Исходные данные}

Экономическая эффективность ФЭП и ВЭУ определяется в первую очередь интенсивностью солнечной радиации, скоростью ветра, техникоэкономическими показателями энергоустановок, а также ценой электроэнергии в энергосистеме.

Мощности ФЭП и ВЭУ зависят от интенсивности солнечного излучения и скорости ветра, которые изменяются как по времени суток, так и по сезонам. Последнее особенно характерно для солнечного излучения [24-28].
Для общей характеристики ветрового и солнечного режимов в пустыне Гоби, а также в качестве ориентира для определения интервала варьирования входных параметров математической модели в табл. 1, 2 приведены данные, характеризующие приход солнечной радиации на горизонтальную и наклонную поверхность солнечных панелей [29] и скорость ветра [30] в некоторых пунктах пустыни Гоби по сезонам года. В расчетах использовались часовые данные $[5,30]$.

При оптимальном расположении (наклоне) солнечных модулей годовой приход солнечной радиации может достигать 1900-2200 кВт.ч/м² [29]. Средняя многолетняя скорость ветра в пустыне Гоби изменяется от 2,5 до $6 \mathrm{~m} / \mathrm{c}$ на высоте 10 м от уровня земли. В 1998-2000 гг. на территории пустыни Гоби проводились измерения с помощью анемометров на высоте 20 м. В населенном пункте Манлай (провинция Умнеговь) измеренная средняя скорость ветра составила 6,6 м/с (6 м/с на высоте 10 м). В ряде других пунктов: в провинциях Умнеговь, Дундговь, Дорноговь средняя многолетняя скорость ветра превышает $5 \mathrm{~m} / \mathrm{c}$ на высоте 10 м и 6 м/с на высоте 20 м [30].

Таким образом, величина прихода солнечной радиации изменяется в достаточно узком интервале и приемлема для развития солнечной энергетики [25]. Ветровые условия изменяются в широком диапазоне; в ряде пунктов ветровые условия хорошие, в других они явно плохие и заведомо не годятся для эффективного использования ветроустановок. 
Таблица 1. Приход солнечной радиачии на горизонтальную поверхность и солнечную панель при оптимальном угле наклона, $\kappa B m \cdot 4 / \mathrm{M}^{2}$

Table 1. Solar radiation input on a horizontal surface and a solar panel at optimum inclination angle, $\mathrm{kWh} / \mathrm{m}^{2}$

\begin{tabular}{|c|c|c|c|c|c|c|}
\hline $\begin{array}{c}\text { Пункт } \\
\text { Point }\end{array}$ & $\begin{array}{c}\text { Расположение } \\
\text { Location }\end{array}$ & 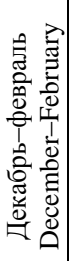 & 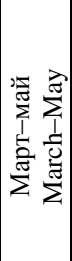 & 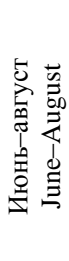 & 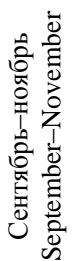 & 总 \\
\hline \multirow{2}{*}{$\begin{array}{l}\text { Мандалговь } \\
\text { Mandalgovi }\end{array}$} & $\begin{array}{c}\text { Горизонт. } \\
\text { Horizon. }\end{array}$ & 203 & 518 & 558 & 309 & 1588 \\
\hline & $\begin{array}{l}\text { Оптим. } \\
\text { Opt. }\end{array}$ & 358 & 573 & 563 & 427 & 1921 \\
\hline \multirow{2}{*}{$\begin{array}{l}\text { Сайншанд } \\
\text { Sainshand }\end{array}$} & $\begin{array}{c}\text { Горизонт. } \\
\text { Horizon. }\end{array}$ & 213 & 521 & 555 & 312 & 1601 \\
\hline & $\begin{array}{l}\text { Оптим. } \\
\text { Opt. }\end{array}$ & 473 & 598 & 560 & 494 & 2125 \\
\hline \multirow{2}{*}{$\begin{array}{l}\text { Даланзадгад } \\
\text { Dalanzadgad }\end{array}$} & $\begin{array}{c}\text { Горизонт. } \\
\text { Horizon. }\end{array}$ & 232 & 529 & 552 & 334 & 1647 \\
\hline & $\begin{array}{c}\text { Oптим. } \\
\text { Opt. }\end{array}$ & 509 & 601 & 556 & 523 & 2189 \\
\hline
\end{tabular}

Примечание: Горизонт. - горизонтальная поверхность, Оптим. - оптимальный наклон панели в зависимости от сезона.

Note: Horizon. - horizontal surface, Opt. - optimal angle of the panel inclination depending on the season.

Таблица 2. Средние многолетние скорости ветра на стандартной высоте $10 \mathrm{M}, \mathrm{M} / \mathrm{c}$

Table 2. Average long-term wind speeds at a standard height of $10 \mathrm{~m}, \mathrm{~m} / \mathrm{s}$

\begin{tabular}{|c|c|c|c|c|c|}
\hline Пункт/Point & $\begin{array}{c}\text { Декабрь- } \\
\text { февраль } \\
\text { December- } \\
\text { February }\end{array}$ & $\begin{array}{c}\text { Март- } \\
\text { май } \\
\text { March-- } \\
\text { May }\end{array}$ & $\begin{array}{c}\text { Июнь- } \\
\text { август } \\
\text { June- } \\
\text { August }\end{array}$ & $\begin{array}{c}\text { Сентябрь- } \\
\text { ноябрь } \\
\text { September-- } \\
\text { November }\end{array}$ & $\begin{array}{c}\text { Bceго } \\
\text { Total }\end{array}$ \\
\hline $\begin{array}{c}\text { Мандалговь } \\
\text { Mandalgovi }\end{array}$ & 3,9 & 5,6 & 4,5 & 4,1 & 4,5 \\
\hline $\begin{array}{c}\text { Сайншанд } \\
\text { Sainshand }\end{array}$ & 4,0 & 5,5 & 4,4 & 4,1 & 4,5 \\
\hline $\begin{array}{c}\text { Даланзадгад } \\
\text { Dalanzadgad }\end{array}$ & 2,2 & 4,7 & 3,6 & 3,3 & 3,5 \\
\hline $\begin{array}{c}\text { Манлай* } \\
\text { Manlai* }\end{array}$ & 6,7 & 7,2 & 5,5 & 6,6 & 6,6 \\
\hline
\end{tabular}

Примечание: * - на высоте расположения анемометра $20 \mathrm{M}$.

Note: * at the height of the anemometer $20 \mathrm{~m}$.

В расчетах использовалась логарифмическая аппроксимация вертикального профиля скорости ветра для установок Goldwind с высотой башни 50 м и единичной номинальной мощностью 1,5 МВт [31]. Номинальная скорость ветра для этих установок - $12 \mathrm{M} / \mathrm{c}$, при скорости ветра $25 \mathrm{~m} / \mathrm{c}$ они прекращают работу во избежание поломки ветротурбины.

График нагрузки потребителей (мощностью 10 ГВт) аналогичен графику для энергосистемы Центра Китая [5]. Технико-экономические показатели компонентов системы электроснабжения приняты по данным [5, 6, 14, 25, 32, 33]. Наиболее важные из них - удельные капиталовложения - составляют для ФЭП 1100 \$/кВт, для ВЭУ - 1300 \$/кВт, для высоковольт- ной ЛЭП постоянного тока длиной 900 км с двумя преобразовательными подстанциями - 840 \$/кВт [5].

\section{Результаты расчетов и их анализ}

Расчеты показывают, что ФЭП в условиях пустыни Гоби могут вырабатывать электроэнергию стоимостью 4-6 цент/кВт·ч, а ВЭУ - 3-9 цент/кВт·ч. Стоимость транспорта электроэнергии составляет 2-3 цент/кВт.ч. В благоприятных для ВИЭ условиях они могут быть конкурентоспособны с угольными (4-7 цент/кВт.ч) и газовыми электростанциями (5-7 цент/кВт·ч), а также с электростанциями на жидком (дизельном) топливе (10-15 цент/кВт.ч) в Монголии и других странах Северо-Восточной Азии.

На рис. 3 сравнивается стоимость электроэнергии солнечных и ветровых электростанций Монголии (пустыня Гоби) и других стран Северо-Восточной Азии по данным [5, 6, 14, 32, 33].

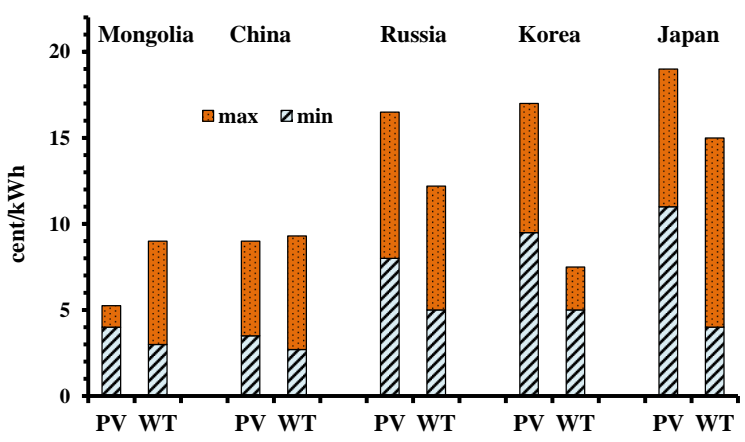

Puc. 3. Стоимость электроэнергии ФЭП и ВЭУ в странах Северо-Восточной Азии. Mongolia - монгольская часть пустыни Гоби, China - Китай, Russia - Россия, Когеа - Республика Корея, Japan - Япония

Fig. 3. Electricity cost of $P V$ and WT in the countries of Northeast Asia

Как видно из рис. 3, в пустыне Гоби ФЭП вырабатывают более дешевую электроэнергию, чем в других странах Северо-Восточной Азии за исключением южных районов Китая. В России стоимость солнечной электроэнергии выше в связи с недостаточным приходом солнечной радиации, а в Японии и Южной Корее - в связи с недостатком площадей и дороговизной сооружения ФЭП и ВЭУ. Стоимость электроэнергии ВЭУ в условиях Монголии несколько выше, чем для аналогичных установок в районах с наилучшими ветровыми условиями в Китае и России, но ниже, чем в Корее и Японии.

На рис. 4 приведены данные расчета оптимального соотношения выработки электроэнергии между ФЭП и ВЭУ при разных ценах электроэнергии в энергосистеме и при различающихся климатических условиях. Цена электроэнергии варьировалась в диапазоне 5-15 цент/кВт·ч для учета неопределенности будущих условий. В частности, цена электроэнергии может вырасти при введении экологического налога на выбросы диоксида углерода [5, 14].

При дешевой энергии из сети (менее 4 цент/кВт·ч) применение ФЭП и ВЭУ не требуется. В районах с 
большим приходом солнечной радиации и плохими ветровыми условиями (рис. 4, $a$ ) при повышении цены электроэнергии становится экономически эффективным применение ФЭП. При цене выше 5 цент/кВт.ч эффективно совместное использование солнечной и ветровой энергии. С увеличением цены электроэнергии повышается доля ВЭУ в суммарной выработке, что обусловлено целесообразностью замещения дорогой энергии энергосистемы более дешевой энергией ветроустановок.

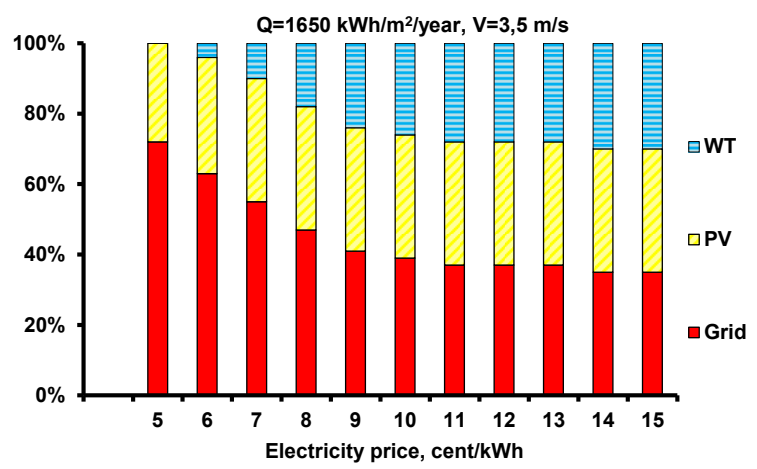

$a$

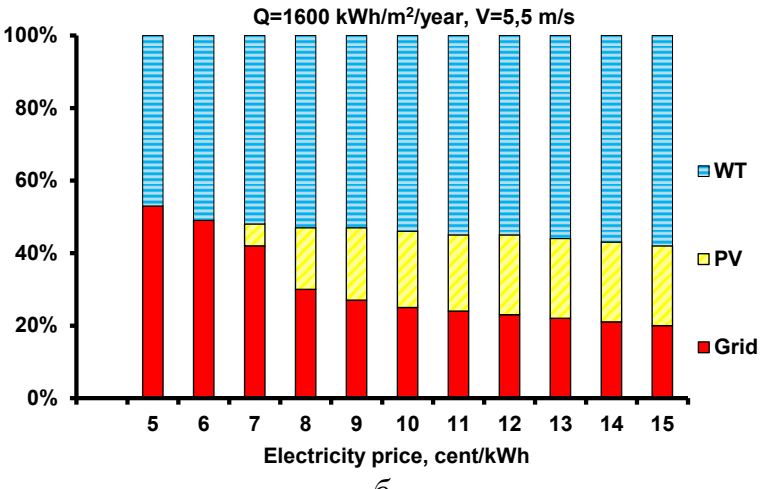

б

Рис. 4. Доля энергоисточников в суммарной выработке при разных иенах электроэнергии в энергосистеме и климатических условиях, \% $(Q-$ годовой приход солнечной радиачии, V-средняя многолетняя скорость ветра, Grid - электроэнергия из сети, Electricity price - цена электроэнергии в энергосистеме)

Fig. 4. Share of energy sources in electricity production at different prices of electricity from the network and climatic conditions $(Q$ is the annual solar radiation input on a horizontal surface, $V$ is average longterm wind speed at a standard height of $10 \mathrm{~m}$, Grid is the electricity from the network)

В районах с хорошими ветровыми условиями (рис. 4, б) при повышении цены на электроэнергию приоритетным является использование ВЭУ (стоимость электроэнергии ВЭУ меньше аналогичного показателя для ФЭП), по мере повышения цены на электроэнергию увеличивается установленная мощность и выработка ФЭП.

Зависимость доли энергоисточников в энергоснабжении потребителей от средней многолетней скорости ветра для ВЭУ показана на рис. 5 при фиксированной цене на электроэнергию от сети
8 цент/кВт.ч. В районах с низкими среднегодовыми скоростями ветра используются только ФЭП. В районах со средней многолетней скоростью ветра (на высоте 10 м) 4 м/с оптимальные мощности ФЭП и ВЭУ примерно равны, более существенны различия в выработке электроэнергии. При средней многолетней скорости ветра 5-6 м/с доля ВИЭ возрастает до 70-75\%, причем совместное использование солнечной и ветровой энергии позволяет уменьшить суммарные затраты на систему электроснабжения на 26-28 \% по сравнению с вариантом использования только солнечной энергии (рис. 6).

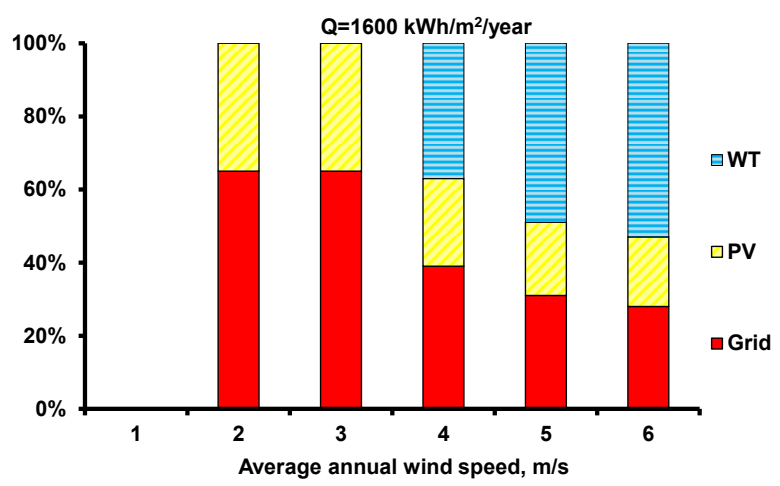

Pис. 5. Зависимость доли энергоисточников в выработке электроэнергии от средней многолетней скорости ветра (при иене электроэнергии от сети 8 иент $/ \kappa$ Вт.ч)

Fig. 5. Dependence of energy sources share in electricity generation on average long-term wind speed (with the price of electricity from the network of 8 cents/kWh)

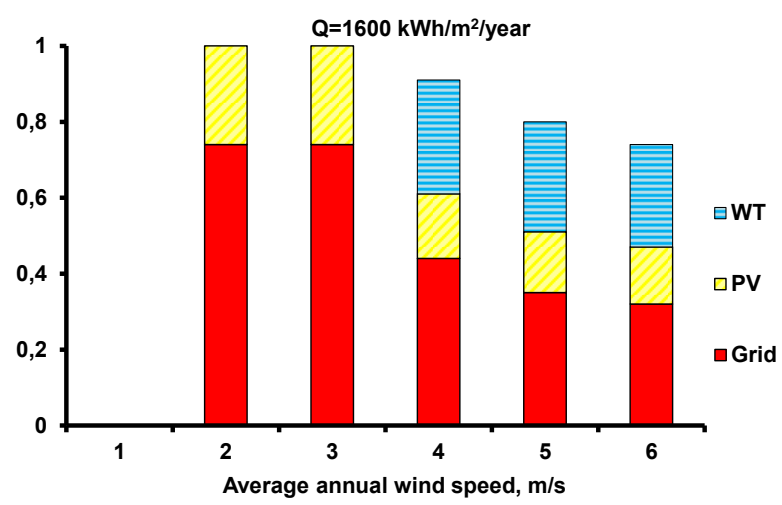

Pис. 6. Зависимость затрат (в относительных единиияах) на электроснабжение от средней многолетней скорости ветра (при цене электроэнергии от сети 8 ичент/кВт.ч)

Fig. 6. Dependence of costs (in relative units) for electricity supply on average long-term wind speed (with the price of electricity from the network of 8 cents $/ \mathrm{kWh}$ )

\section{Заключение}

Определена оптимальная структура и выполнена оценка экономической эффективности ветровых и солнечных электростанций в монгольской части пустыни Гоби для различных сочетаний экономических и климатических условий. 
Для оптимизации структуры системы электроснабжения использовалась математическая модель REM-2 (Renewable Energy Model). C помощью моделирования режимов работы ФЭП и ВЭУ по времени (часам) для различных значений прихода солнечной радиации и скорости ветра определены оптимальные соотношения между мощностями возобновляемых источников энергии, производством электроэнергии фотоэлектрическими преобразователями и ветротурбинами, а также поставками электроэнергии из энергосистем Северного и Северо-Восточного Китая, которые компенсируют неравномерность выработки ВИЭ.

ФЭП в условиях пустыни Гоби могут вырабатывать электроэнергию стоимостью 4-6 цент/кВт·ч, а ВЭУ - 3-9 цент/кВт·ч. Стоимость транспорта электроэнергии в Китай составляет 2-3 цент/кВт.ч. В благоприятных для ВИЭ условиях они могут быть конкурентоспособны с угольными и газовыми электро-

\section{СПИСОК ЛИТЕРАТУРЫ}

1. Россия в Евразийской электроэнергетической интеграции О.В. Марченко, С.В. Подковальников, В.А. Савельев, С.В. Соломин, Л.Ю. Чудинова // Мировая экономика и международные отношения. - 2018. - Т. 62. - № 6. - С. 18-29.

2. Podkovalnikov S.V., Savelyev V.A., Chudinova L.Y. Prospects of electric-energy cooperation between Russia and northeast Asian countries // Studies on Russian Economic Development. - 2015. V. 26. - № 4. - P. 403-412.

3. Mongolia's potential in international cooperation in the Asian energy space / S. Batmunkh, V. Stennikov, B. Bat-Erdene, A. Erdenebaatar // E3S Web of Conferences. - 2018. - V. 27. № 01006. - P. 1-10.

4. Bogdanov D., Breyer C. North-East Asian Super Grid for $100 \%$ renewable energy supply: optimal mix of energy technologies for electricity, gas and heat supply options // Energy Conversion and Management. - 2016. - V. 112. - P. 176-190.

5. Otsuki T., Mohd Isa A.B., Samuelson R.D. Electric Power Grid interconnections in Northeast Asia: a quantitative analysis of opportunities and challenges // Energy Policy. - 2016. - V. 89. P. 311-329.

6. Otsuki T. Costs and benefits of large-scale deployment of wind turbines and solar PV in Mongolia for international power exports // Renewable Energy. - 2017. - V. 108. - P. 321-335.

7. GOBITEC and Asian Super Grid for renewable energies in Northeast Asia / S. Mano, B. Ovgor, Z. Samadov, M. Pudlik, V. Jülich, D. Sokolov, J. Y. Yoon. - Sofia: Spotinov print Ltd, 2014. - 114 p.

8. Study on the local climatic effects of large photovoltaic solar farms in desert areas exports / L. Yang, X. Gao, F. Lv, X. Hui, L. Ma, X. Hou // Solar Energy. - 2017. - V. 144. - P. 244-253.

9. Middleton N.J. Desert dust hazards: a global review // Aeolian Research. - 2017. - V. 24. - P. 53-63.

10. A preliminary study on potential for very large-scale photovoltaic power generation (VLS-PV) system in the Gobi desert from economic and environmental viewpoints / M. Ito, K. Kato, H. Sugiharac, T. Kichimid, J. Songe, K. Kurokawa // Solar Energy Materials \& Solar Cells. - 2003. - V. 75. - P. 507-517.

11. Bhargava A. Developing the Northeast Asia regional energy market. - Manila: ADB, 2017. - 14 p.

12. Global Energy Interconnection Development Index 2018. Beijing: Global Energy Interconnection Development Organisation, 2018. - 112 p.

13. Марченко О.В., Соломин С.В. Исследование влияния экологических ограничений на конкурентособность атомных электростанций // Известия высших учебных заведений. Ядерная энергетика. - 2015. - № 3. - С. 20-30.

14. Марченко О.В., Соломин С.В. Влияние платы за выбросы диоксида углерода на конкурентособность электростанций в станциями, а также с электростанциями на дизельном топливе в Монголии и других странах СевероВосточной Азии, прежде всего в Китае.

Показана экономическая эффективность совместного использования солнечной и ветровой энергии в монгольской части пустыни Гоби за исключением некоторых районов с низкими средними многолетними скоростями ветра. Оптимальная доля ВИЭ составляет 70-75 \% при средней многолетней скорости ветpa 5-6 м/с. За счет совместного использования ветровой и солнечной энергии можно снизить затраты на электроснабжение более чем на четверть по сравнению с вариантом использования только солнечной энергии.

Работа выполнена в рамках проекта государственного задания III.17.6.2 (рег. № АAAA-A17-117030310447-3) фундаментальных исследований СО РАН.

России и в некоторых странах Азии // Энергетик. - 2018. № 9. - C. 27-30.

15. Lilienthal P. The HOMER micropower optimization model. Golden, Colorado: National Renewable Energy Laboratory, 2005. $-5 \mathrm{p}$.

16. Lambert T., Gilman P., Lilienthal P. Micropower system modeling with HOMER. URL: https://www.homerenergy.com/documents/ MicropowerSystemModelingWithHOMER.pdf (дата обращения 18.01.2019).

17. TRNSYS. Transient system simulation tool. URL: http://www.trnsys.com (дата обращения 18.01.2019).

18. Mathematical modeling of hybrid renewable energy system: a review on small hydro-solar-wind power generation / B. Bhandari, S.R. Poudel, K.-T. Lee, S.-H. Ahn // International Journal of Precision Engineering and Manufacturing-Green Technology. 2014. - V. 1. - № 2. - P. 157-173.

19. Evaluating the value of batteries in microgrid electricity systems using an improved Energy Systems Model / E. Hittinger, T. Wiley, J. Kluza, J. Whitacre // Energy Conversion and Management. 2015. - V. 89. - P. 458-472.

20. Energy management strategies in hybrid renewable energy systems: a review / L. Olatomiwa, S. Mekhies, M.S. Ismail, M. Moghavvemi // Renewable and Sustainable Energy Reviews. 2016. - V. 62. - P. 821-835.

21. Erdinc O., Uzunoglu M. Optimum design of hybrid renewable energy systems: Overview of different approaches // Renewable and Sustainable Energy Reviews. - 2012. - V. 16. - P. 1412-1425.

22. Dynamical Simulation of PV/Wind Hybrid Energy Conversion System / V. Bakić, M. Pezo, Ž. Stevanović, M. Živković, B. Grubor // Energy. - 2012. - V. 45. - № 1. - P. 324-328.

23. Multi-turbine wind-solar hybrid system / Q. Huang, Y. Shi, Y. Wang, L. Lu, Y. Cui // Renewable Energy. - 2015. - V. 76. № 4. - P. 401-407.

24. Marchenko O.V. Mathematical modeling and economic efficiency assessment of autonomous energy systems with production and storage of secondary energy carriers // International Journal of Low-carbon Technologies. - 2010. - V. 10. - № 5. - P. 250-255.

25. Marchenko O.V., Solomin S.V. Efficiency of hybrid renewable energy systems in Russia // International Journal of Renewable Energy Research. - 2017. - V. 7. - № 4. -P. 1561-1569.

26. Карамов Д.Н. Математическое моделирование солнечной радиации с использованием многолетних метеорологических рядов, находящихся в открытом доступе // Известия Томского политехнического университета. Инжиниринг георесурсов. 2017. - Т. 238. - № 6. - С. 28-37.

27. Карамов Д.Н. Формирование исходных метеорологических массивов с использованием многолетних рядов FM 12 SYNOP и METAR в системных энергетических исследованиях // Известия Томского политехнического университета. Инжиниринг георесурсов. - 2018. - Т. 239. - № 1. - С. 69-88.

28. Обухов С.Г., Плотников И.А. Выбор параметров и анализ эффективности применения систем слежения за Солнцем // 
Известия Томского политехнического университета. Инжиниринг георесурсов. - 2018. - Т. 239. - № 10. - С. 95-106.

29. Boxwell M. The Solar Electricity Handbook. 2017 Edition. Birmingham: Greenstream Publishing, 2017. - 206 p. URL: http://solarelectricityhandbook.com/solar-irradiance.html (дата обращения 16.01.2019).

30. Wind energy resource atlas of Mongolia / D. Elliott, M. Schwartz, G. Scott, S. Haymes, D. Heimiller, R. George. - Colorado: NREL/TP-500-28972, 2001. $-215 \mathrm{p}$.

31. World leader in PMDD turbine technology. Goldwind. URL: https://www.goldwindamericas.com/ (дата обращения 18.01.2019).

\section{Информация об авторах}

Марченко О.B., кандидат технических наук, старший научный сотрудник Института систем энергетики им. Л.А. Мелентьева Сибирского отделения Российской академии наук.

Соломин C.B., кандидат технических наук, старший научный сотрудник Института систем энергетики им. Л.А. Мелентьева Сибирского отделения Российской академии наук.
32. Projected costs of generating electricity / M. Wittenstein, G. Rothwell, C. Yu, M. Defferenes, H. Paillere, U. Remme et al. Paris: International Energy Agency/Nuclear Energy Agency, 2015. $-215 \mathrm{p}$

33. Marchenko O.V., Solomin S.V. Economic efficiency of renewable energy sources in Russia // International Journal of Renewable Energy Research. - 2014. - V. 4. - № 3. - P. 548-554.

Поступила 14.05.2019 г. 
UDC 620.9

\title{
DETERMINATION OF THE OPTIMAL STRUCTURE OF WIND-SOLAR POWER PLANTS IN THE MONGOLIAN PART OF THE GOBI DESERT
}

\author{
Oleg V. Marchenko1, \\ marchenko@isem.irk.ru \\ Sergei V. Solomin', \\ solomin@isem.irk.ru \\ 1 Melentiev Energy Systems Institute of Siberian Branch of the Russian Academy of Sciences,
130, Lermontov street, Irkutsk, 664033, Russia.
}

The relevance of the work is caused by the intensive economic development of the countries of Northeast Asia, the increase in their electricity demand and feasibility of improving the economic and environmental efficiency of electricity supply through the implementation of electrical energy integration projects. In this case, the large-scale introduction of renewable energy sources can play an important role. The aim of the research is to determine the optimal structure of wind power plants in the Mongolian part of the Gobi Desert (the ratio of the capacities of different types of power plants and their generation of electricity) for different combinations of economic and climatic conditions.

Methods: systematization of climatic and meteorological information, preliminary assessment of the effectiveness of energy sources of various types according to the criterion of the cost of electricity produced, mathematical modeling of the structure and modes of operation of the power system. The mathematical model takes into account the random nature of solar and wind energy.

Results. It is shown that the electricity produced by photoelectric converters and wind turbines, taking into account the cost of its transport along power transmission lines, is competitive in the electricity markets of China and other countries of Northeast Asia. For various values of solar radiation input and wind speed, the optimum ratios were determined between the capacities of renewable energy sources, the production of electricity by photoelectric converters and wind turbines, as well as the supply of electricity from China's power system to compensate the unevenness in production of renewable energy sources. The economic efficiency of joint use of solar and wind energy in the Mongolian part of the Gobi desert is shown, with the exception of some areas with low wind speeds. The combined use of solar and wind energy allows reducing the total costs in the power supply system by more than a quarter compared with the variant of using only solar energy.

\section{Key words:}

Gobi Desert, Mongolia, power system, renewable energy sources, effectiveness, electricity price.

The research was carried out under State Assignment, Project III.17.6.2 (reg. no. AAAA-A17-117030310447-3) of the Fundamental Research of Siberian Branch of the Russian Academy of Sciences.

\section{REFERENCES}

1. Marchenko O.V., Podkovalnikov S.V., Savelyev V.A., Solomin S.V., Chudinova L.Y. Russia in Eurasian electric power integration. World Economy and International Relations, 2018, vol. 62, no.6, pp. 18-29. In Rus.

2. Podkovalnikov S.V., Savelyev V.A., Chudinova L.Y. Prospects of electric-energy cooperation between Russia and northeast Asian countries. Studies on Russian Economic Development, 2015, vol. 26, no. 4, pp. 403-412.

3. Batmunkh S., Stennikov V., Bat-Erdene B., Erdenebaatar A. Mongolia's potential in international cooperation in the Asian energy space. E3S Web of Conferences, 2018, vol. 27, no. 01006, pp. 1-10.

4. Bogdanov D., Breyer C. North-East Asian Super Grid for $100 \%$ renewable energy supply: Optimal mix of energy technologies for electricity, gas and heat supply options. Energy Conversion and Management, 2016, vol. 112, pp. 176-190.

5. Otsuki T., Mohd Isa A. B., Samuelson R. D. Electric Power Grid Interconnections in Northeast Asia: A Quantitative Analysis of Opportunities and Challenges. Energy Policy, 2016, vol. 89, pp. 311-329.

6. Otsuki T. Costs and benefits of large-scale deployment of wind turbines and solar PV in Mongolia for international power exports. Renewable Energy, 2017, vol. 108, pp. 321-335.

7. Mano S., Ovgor B., Samadov Z., Pudlik M., Jülich V., Sokolov D., Yoon J.Y. GOBITEC and Asian Super Grid for Renewable Energies in Northeast Asia. Sofia, Spotinov print Ltd, 2014. 114 p.

8. Yang L., Gao X., Lv F., Hui X., Ma L., Hou X. Study on the local climatic effects of large photovoltaic solar farms in desert areas exports. Solar Energy, 2017, vol. 144, pp. 244-253.
9. Middleton N.J. Desert dust hazards: a global review. Aeolian Research, 2017, vol. 24, pp. 53-63.

10. Ito M., Kato K., Sugiharac H., Kichimid T., Songe J., Kurokawa K. A preliminary study on potential for very large-scale photovoltaic power generation (VLS-PV) system in the Gobi desert from economic and environmental viewpoints. Solar Energy Materials \& Solar Cells, 2003, vol. 75, pp. 507-517.

11. Bhargava A. Developing the Northeast Asia regional energy market. Manila, ADB, 2017. 14 p.

12. Global Energy Interconnection Development Index 2018. Beijing, Global Energy Interconnection Development Organisation, 2018. $112 \mathrm{p}$.

13. Marchenko O.V., Solomin S.V. Investigation of ecological constraints influence on competitiveness of nuclear power plants. Izvestiya Vysshikh Uchebnykh Zawedeniy, Yadernaya Energetika, 2015, no. 3, pp. 20-30. In Rus.

14. Marchenko O.V., Solomin S.V. Effect of carbon tax on the competitiveness of power stations in Russia and in some countries of Asia. Energetik, 2018, no. 9, pp. 27-30. In Rus.

15. Lilienthal P. The HOMER micropower optimization model. Golden, Colorado, National Renewable Energy Laboratory, 2005. $5 \mathrm{p}$.

16. Lambert T., Gilman P., Lilienthal P. Micropower system modeling with HOMER. Available at: https://www.homerenergy.com/ documents/MicropowerSystemModelingWithHOMER.pdf (accessed 18 January 2019).

17. TRNSYS. Transient system simulation tool. Available at: http://www.trnsys.com (accessed 18 January 2019).

18. Bhandari B., Poudel S.R., Lee K.-T., Ahn S.-H. Mathematical modeling of hybrid renewable energy system: a review on small 
hydro-solar-wind power generation. International Journal of Precision Engineering and Manufacturing-Green Technology, 2014, vol. 1, no. 2, pp. 157-173.

19. Hittinger E., Wiley T., Kluza J., Whitacre J. Evaluating the value of batteries in microgrid electricity systems using an improved Energy Systems Model. Energy Conversion and Management, 2015, vol. 89. pp. 458-472.

20. Olatomiwa L., Mekhies S., Ismail M.S., Moghavvemi M. Energy management strategies in hybrid renewable energy systems: a review. Renewable and Sustainable Energy Reviews, 2016, vol. 62, pp. 821-835.

21. Erdinc O., Uzunoglu M. Optimum design of hybrid renewable energy systems: Overview of different approaches. Renewable and Sustainable Energy Reviews, 2012, vol. 16, pp. 1412-1425.

22. Bakić V., Pezo M., Stevanović Ž., Živković M., Grubor B. Dynamical Simulation of PV/Wind Hybrid Energy Conversion System. Energy, 2012, vol. 45, no. 1, pp. 324-328.

23. Huang Q., Shi Y., Wang Y., Lu L., Cui Y. Multi-turbine windsolar hybrid system. Renewable Energy, 2015, vol. 76, no. 4, pp. 401-407.

24. Marchenko O.V. Mathematical modeling and economic efficiency assessment of autonomous energy systems with production and storage of secondary energy carriers. International Journal of Low-carbon Technologies, 2010, vol. 10, no. 5, pp. 250-255.

25. Marchenko O.V., Solomin S.V. Efficiency of hybrid renewable energy systems in Russia. International Journal of Renewable Energy Research, 2017, vol. 7, no. 4, pp. 1561-1569.

26. Karamov D.N. Mathematical modeling of solar radiation based on open access long-term meteorological observation data. Bulletin of

\section{Information about the authors}

Oleg V. Marchenko, Cand. Sc, senior researcher, Melentiev Energy Systems Institute of Siberian Branch of the Russian Academy of Sciences.

Sergei V. Solomin, Cand. Sc, senior researcher, Melentiev Energy Systems Institute of Siberian Branch of the Russian Academy of Sciences. the Tomsk Polytechnic University. Geo Assets Engineering, 2017, vol. 328, no. 6, pp. 28-37. In Rus.

27. Karamov D.N. Formation of initial meteorological arrays using long-term series FM 12 SYNOP and METAR in system energy studies. Bulletin of the Tomsk Polytechnic University. Geo Assets Engineering, 2018, vol. 329, no. 1, pp. 69-88. In Rus.

28. Obukhov S.G., Plotnikov I.A. Choosing the parameters and analyzing the efficiency of tracking systems. Bulletin of the Tomsk Polytechnic University. Geo Assets Engineering, 2018, vol. 329, no. 10, pp. 95-106. In Rus.

29. Boxwell M. The Solar Electricity Handbook. 2017 Edition. Birmingham, Greenstream Publ., 2017. 206 p. Available at: http://solarelectricityhandbook.com/solar-irradiance.html (accessed 16 January 2019).

30. Elliott D., Schwartz M., Scott G., Haymes S., Heimiller D., George R. Wind energy resource atlas of Mongolia. Colorado, NREL/TP-500-28972, 2001. $215 \mathrm{p}$.

31. World leader in PMDD turbine technology. Goldwind. Available at: https://www.goldwindamericas.com/ (accessed 18 January 2019).

32. Wittenstein M., Rothwell G., Yu C., Defferenes M., Paillere H., International Energy Agency/Nuclear Energy Agency, 2015. 215 p.

33. Marchenko O.V., Solomin S.V. Economic efficiency of renewable energy sources in Russia. International Journal of Renewable Energy Research, 2014, vol. 4, no. 3, pp. 548-554.

Received: 14 May 2019. Remme U. Projected costs of generating electricity. Paris, 